\title{
Mengembangkan Pendidikan Agama Inklusif sebagai Solusi Pengelolaan Keragaman di Indonesia
}

\author{
Yance Z. Rumahuru \\ Institut Agama Kristen Negeri Ambon \\ rumahuru@yahoo.com
}

\begin{abstract}
This article discusses the importance of inclusive religious education as an instrument for building and developing a model of contextual religious education in Indonesia. This discussion aims to provide alternative thinking to correct the reality of exclusive religious practices that are thought to be influenced by ways of learning religion in schools that have not been able to change and shape Naradidik's inclusive attitude. From the results of various literature studies, it was found that in addition to the widely commented education politics and religious education system, religious education built on an exclusive paradigm has helped shape attitudes of hatred and intolerance among narrators, which can be used as fertile ground for the growth of radicalism and extremism. It was found that inclusive religious education that pays attention to efforts to build awareness of differences can be an effective model that transforms religious education in the context of this pluralistic society in Indonesia. Inclusive religious education is also a medium of religious learning that can shape the moderate attitude of students. In this regard inclusive religious education can be used as a solution for strengthening attitudes towards other groups outside of their own groups and managing diversity in Indonesia.
\end{abstract}

Keywords: inclusive, diversity, religious education

\begin{abstract}
Abstrak: Artikel ini mendiskusikan pentingnya pendidikan agama inklusif sebagai instrumen untuk membangun dan mengembangkan satu model pendidikan agama kontekstual di Indonesia. Pembahasan ini bertujuan memberi pemikiran alternatif untuk mengoreksi realitas praktik keagamaan eksklusif yang diduga turut dipengaruhi oleh cara pembelajaran agama di sekolah yang belum mampu mengubah dan membentuk sikap inklusif naradidik. Dari hasil kajian berbagai literatur ditemuai bahwa selain politik pendidikan dan sistem pendidikan agama di Indonesia yang banyak dikomentari, pendidikan agama yang dibangun dalam paradigma eksklusif telah turut membentuk sikap kebencian dan intoleransi di kalangan naradidik, yang dapat dijadikan lahan subur tumbuhnya gerakan radikalisme dan ekstrimisme. Ditemui bahwa pendidikan agama inklusif yang memberi perhatian pada upaya membangun penyadaran terhadap perbedaan dapat dijadikan model efektif yang mentransformasi pendidikan keagamaan dalam konteks bermasyarakat di Indonesia yang majemuk ini. Pendidikan agama inklusif sekaligus menjadi media pembelajaran agama yang dapat membentuk sikap moderat nara didik. Dalam kaitan ini pendidikan agama inklusif dapat dijadikan salah satu solusi bagi penguatan sikap penerimaan terhadap kelompok lain di luar kelompok sendiri dan pengelolaan keragaman di Indonesia.
\end{abstract}

Kata Kunci: inklusif, keragaman, pendidikan agama 


\section{Pendahuluan}

Pendidikan agama telah dijadikan mata pelajaran utama di Indonesia mulai dari Sekolah Dasar (SD) hingga Perguruan Tinggi (PT), tetapi sikap beragama di Indonesia menunjukkan bahwa penghargaan terhadap sesama umat bergama jauh dari apa yang diharapkan. ${ }^{1}$ Adakah yang salah dengan pendidikan agama yang diberi? Bagaimana sistim pendidikan agama? Bagaimana kurikulum pendidikan agama? Bagaimana materi ajar pendidikan agama? Berapa jam pembelajaran agama? Mengapa panatisme sempit agama, penistaan agama, radikalisme agama dan ekstrimisme agama mendapat tempat di Indonesia yang masyarakatnya religious dan banyak mempelajari agama dibanding warga bangsa dan negara lain? Pertanyaan-pertanyaan ini dan serupanya dapat diurut lebih banyak lagi untuk menunjukkan bahwa memang ada masalah serius dengan pendidikan agama di Indonesia. Oleh karenanya perlu dilihat secara bersama apa yang salah dengan pemberian mata pelajaran agama sebagai menu wajib setiap siswa dan mahasiswa di Indonesia.

Pertanyaan-pertanyaan yang dikemukakan ini kiranya menginterupsi setiap orang sebagai pengajar agama bahkan sebagai lembaga-lembaga pendidikan yang memproduksi pengajar-pengajar agama dan orang-orang yang memberi literasi agama di masyarakat secara luas, betapa agama sekalipun telah disajikan layaknya menu wajib bagi setiap warga Negara sejak SD hingga PT tetapi pendidikan agama belum banyak berkontribusi menjadi pondasi membangun sikap inklusif para peserta didik, dan memengaruhi masyarakat untuk saling menghargai keragaman dan mengelolanya sebagai modal penting pembangunan bangsa. Apabila dicermati kehidupan umat beragama di Indonesia, dapat disebut bahwa ekspersi beragama akhir-akhir ini di Indonesia menunjukkan adanya resistensi yang tinggi di kalangan pemeluk agama. Padahal, semestinya pendidikan agama yang telah menjadi menu wajib siswa dan mahasiswa di Indonesia menjadi modal utama memupuk kesadaran tentang kemajemukan.

Sejak masa pemerintahan Orde Baru, pendidikan Agama ditetapkan menjadi mata pelajaran wajib di sekolah dasar hingga perguruan tinggi, dengan tujuan agar pendidikan agama yang diberi kepada setiap warga Indonesia dapat memproteksi paham komunisme. Pada masa reformasi hingga kini, gagasan serupa mengalami modifikasi yang melihat tugas dunia pendidikan secara umum dan khususnya posisi pendidikan agama adalah untuk "memperkuat keyakinan beragama.,"2

Tulisan ini membahas pertanyaan utama, bagaimana problematika pendidikan agama di Indonesia dan bagaimana pula solusi terhadap penyelenggaraan pendidikan agama untuk membangun sikap saling menghargai dan menerima dalam kemajemukan? Kemajemukan sebagaimana dimaksud dalam tulisan ini tidak hanya terbatas pada kemajemukan agama tetapi juga budaya, sosial, ekonomi, idiologi, gender dan sebagainya, yang sejak

\footnotetext{
${ }^{1}$ Rumahuru, Y.Z., 2014, Keragaman Sebagai Basis Pembelajaran PAK, Jurnal Mara Christy Vol. V. No. 2, Juli-Desember 2014 Ambon: STAKPN Ambon.

${ }^{2}$ Suhadi dkk, Politik Pendidikan Agama, Kurikulum 2013 di Ruang Publik Sekolah, Yogyakarta: CRCS UGM, 2014
} 
pembentukan Negara Kesatuan Republik Indonesia (NKRI) sudah disadari eksistensinya oleh pendiri bangsa ini. Pengabaian terhadap kemajemukan yang dimiliki bangsa ini sama artinya dengan penyangkalan terhadap eksistensi NKRI.

Dengan lain perkataan, apabila realitas keragaman bangsa Indonesia terus dipertentangkan dan tidak dikelolah sebagai kekuatan penting membangun bangsa ini maka, disadari atau tidak hal tersebut akan menjadi ancaman disintegrasi bangsa. Oleh karena itu sudah sepatutnya dicarikan model-model pendidikan yang dapat membentuk sikap moderat dan inklusif nara didik. Pendidikan agama inklusif yang dibahas pada tulisan ini dapat dijadikan salah satu alternatif mengoreksi model-model pendidikan agama eksklusif yang mengabaikan realitas kemajemukan.

\section{Pembahasan}

\section{Pendidikan Inklusif: suatu kerangka konseptual}

Pendidikan inklusif disini dapat dipahami sebagai bagian dari pendidikan untuk membangun penyadaran terhadap perbedaan, sehingga menjadi bagian dari upaya mengelolah keragaman dan upaya bina damai. Dalam perspektif seperti dikemukakan maka, pendidikan inklusif merupakan proses transformasi pendidikan dari masa krisis dimana kelompok-kelompok masyarakat belum memahami pentingnya bina damai yang menurut hemat penulis efektif dikonstruksi melalui pendidikan formal. Oleh karena itu, kerangka konseptual yang dapat membantu untuk memahami pendidikan inklusif adalah konsep tentang pendidikan perdamaian dan pendidikan multikultur.

Kedua konsep ini dapat digunakan secara bersama dengan alasan, pendidikan multikultural dapat membantu pengembangan pendidikan perdamaian dengan memakai keberagamaan identitas, budaya, agama, dan ekspresi manusia, bahkan konflik dan krisis, sebagai titik berangkat pendidikan. Pendidikan multikultural juga membantu pendidikan perdamaian dalam hal keyakinannya bahwa manusia sanggup belajar dan berefleksi terhadap pengalaman hidup mereka, baik belajar dari masa lalu untuk memahami masa kini, maupun masa depan yang diharapkan terkait dengan struktur dan relasi multikultural. Refleksi ini kemudian membawa pada aksi, yang selanjutnya akan menjadi bahan refleksi yang baru, dan seterusnya.

Dalam pandangan Tabita Kartika Christiani, pendidikan perdamaian tidak cukup berhenti sampai refleksi tetapi patut diikuti dengan aksi, yaitu bekerja untuk mengupayakan perdamaian, untuk mengubah situasi masa kini yang tidak damai. ${ }^{3}$ Dalam perspektif pendidikan perdamaian, pendidikan merupakan proses transformasi ke arah masa depan, sehingga pendidikan menjadi bagian integral dari proses "transformasi" pada kerangka pengembangan perdamaian itu, untuk mentransformasi krisis atau konflik masa

\footnotetext{
${ }^{3}$ Tabita K.Christiani, "Blessed are The Peacemakers: Christian Religious Education for Peacebuilding in The Pluralistic Indonesian Context", Dissertation, The Graduate School of Arts and Sciences Instutute of Religious Education and Pastoral Ministery of Boston College, 2005.
} 
kini menuju struktur dan relasi sosial yang diharapkan. Pendidikan adalah proses panjang, yang membutuhkan waktu beberapa generasi untuk mencapai masa depan yang diharapkan. ${ }^{4}$

Pemikiran yang dikemukakan sejalan dengan pandangan Dewey bahwa pendidikan adalah perkembangan yang terjadi di dalam, oleh, dan untuk pengalaman. Namun demikian tidak semua pengalaman bersifat edukatif; hanya pengalaman yang membangun dan direfleksikan saja yang bersifat edukatif. Kita dapat belajar dari pengalaman jika kita berpikir, berefleksi, merekonstruksi dan mengajukan pertanyaan kritis terhadap pengalaman itu. Oleh karena itu dalam proses pendidikan naradidik perlu belajar untuk berpikir secara kritis untuk melihat pentingnya pengalaman itu serta berefleksi terhadap pengalaman nyata untuk belajar darinya. Dalam perspektif ini menurut Dewey pendidikan merupakan proses yang disengaja, agar naradidik memperoleh kesempatan untuk merekonstruksi pengalaman mereka. Guru sebagai pembimbing dan rekan sekerja dari naradidik membantu mereka untuk "menemukan melalui pengalaman apa yang telah ditemukan oleh komunitas sebagai pengalaman turun temurun., 5

Konsep pendidikan multikultur di sini menggunakan pemikiran James A. Banks yang melihat bahwa pendidikan multikultural bermula dari ide tentang "semua murid, apapun latar belakang jenis kelamin, etnis, ras, budaya, kelas sosial, agama, atau perkecualiannya, harus mengalami kesederajatan pendidikan di sekolah-sekolah." "Dalam hal ini "kultur" tidak hanya bersangkut paut dengan budaya tradisional yang mencakup aturan bertingkah laku, bahasa, ritual-ritual, seni, cara atau gaya berpakaian, cara-cara menghasilkan dan mengolah makanan, tetapi juga mencakup konstruksi sosial, sehingga terdapat kelas sosial, sistem-sistem politik dan ekonomi, teknologi, dan secara khusus agama. Pemahaman yang luas ini merupakan pemahaman yang lebih baru, yang mengembangkan pemahaman lama bahwa multikulturalisme hanya bersangkut paut dengan keberagaman etnis. $^{7}$

Pendidikan multikultural yang dipromosikan oleh James Banks menunjukkan adanya empat tingkat pengintegrasian pemahaman multikultural ke dalam kurikulum. ${ }^{8}$ Tingkat pertama, pendekatan kontribusi (the contributions approach), sekedar menambahkan unsurunsur budaya tradisional seperti makanan, tarian, musik, dan kerajinan tangan, tanpa memberikan perhatian pada makna dan pentingnya unsur-unsur itu dalam komunitas

\footnotetext{
${ }^{4}$ Ibid.

${ }^{5}$ John Dewey, Experience and Education, First Collier books ed., The Kappa Delta Pi Lecture Series. (New York: Touchstone, 1997), 38

${ }^{6}$ James A Banks, "Multicultural Education: Characteristics and Goal," dalam Multicultural Education: Issues and Perspectives, ed. James A. Banks and Cherry A. McGee Banks (New York: Jhon Willey \& Sons.Inc, 2001), 25.

${ }^{7}$ Antone Hope S, Pendidikan Kristiani Kontekstual: Mempertimbangkan Realitas Kemajemukan dalam Pendidikan Agama (Jakarta: BPK Gunung Mulia, 2010); band. H.A.R Tilaar, Pendidikan, Kebudayaan, dan Masyarakat Madani Indonesia: Strategi Reformasi Nasional. Bandung: Penerbit PT Remaja Rosdakarya, 2000;, Multikulturalisme: Tantangan-Tantangan Global Masa Depan dalam Transformasi Pendidikan Nasinal (Jakarta: Grasindo, 2004).

${ }^{8}$ Banks, "Multicultural Education: Characteristics and Goal," 230-236
} 
etniknya. Tingkat ini merupakan pengintegrasian pada permukaan belaka. Akibatnya naradidik dapat memahami unsur-unsur budaya itu sebagai pengalaman asing yang terpisah dari kelompok mereka sendiri. Tingkat kedua, pendekatan penambahan (the additive approach), guru menambahkan berbagai isi, konsep, tema dan perspektif ke dalam kurikulum tanpa mengubah struktur, tujuan, dan karakteristik yang mendasar. Misalnya dengan menambahkan sebuah buku, unit atau mata pelajaran ke dalam kurikulum. Memang tingkat penambahan ini lebih mendalam dibandingkan tingkat pertama, namun kedua tingkat tersebut tidak merestrukturisasi kurikulum utama yang mempunyai berbagai bias.

Tingkat ketiga, pendekatan transformasi (the transformation approach), asumsiasumsi mendasar dari kurikulum diubah agar dapat memampukan naradidik melihat konsep-konsep, isu-isu, tema-tema, dan problem-problem dari berbagai perspektif dan sudut pandang. Akhirnya, tingkat keempat, yang disebut pendekatan aksi sosial (the social action approach), bertujuan memberdayakan naradidik dan membantu mereka mencapai kesadaran politik. Naradidik dimampukan untuk menjadi pengkritik sosial yang reflektif dan partisipan yang terampil dalam melakukan perubahan sosial.

\section{Problem Pendidikan Agama di Indonesia}

Untuk melihat seperti apa masalah pendidikan Agama di Indonesia penulis merujuk pada dua kajian sebelum terkait permasalahan ini. Pertama, Muh. Saerozi yang mengkaji tentang politik pendidikan agama dalam era pluralisme di Indonesia ${ }^{9}$, menemukan bahwa kebijakan negara tentang pola pendidikan agama dilakukan dalam dua pola: (a) pola konfensional, yaitu negara memberikan legitimasi pendidikan agama untuk meningkatkan keimanan dan ketakwaan subjek didik pada setiap agama; (b) pola nonkonfensional, yaitu negara memberikan legitimasi memperkenalkan berbagai agama di sekolah untuk menyadari adanya berbagai kepercayaan yang diyakini oleh kelompok-kelompok dalam masyarakat. Unsur konfensional dalam kebijakan pendidikan di Indonesia tampak dalam beberapa aspek: (1) pendekatan pendidikan agama yang teologis, tetapi terkontrol dengan pendekatan lain yang bekerja kontekstual. (2) pendidikan yang diisyaratkan beriman dan bertakwa kepada Tuhan Yang Maha Esa. (3) praktik ibadah dan acara-acara keagamaan yang dilakukan di sekolah negeri. (4) pendanaan pendidikan yang dialokasikan bukan hanya untuk lembaga pendidikan negeri bersifat umum, tetapi juga keagamaan, dan swasta berciri khusus agama.

Kedua, Listia, dkk. ${ }^{10}$ memublikasi hasil penelitian interfidei tentang problematika pendidikan agama di sekolahdengan mengambil setting tempat Kota Yogyakarta 2004-

\footnotetext{
${ }^{9}$ Saerozi, Muh., Politik Pendidikan Agama dalam Era Pluralisme: Telaah Historis atas Kebijakan Pendidikan Agama Konfensional di Indonesia (Yogyakarta: Program Pascasarjana UIN Sunan Kalijaga, 2003).

${ }^{10}$ Listia, dkk., 2007, Probelamtika Pendidikan Agama di Sekolah (Hasil Penelitian Tentang Pendidikan Agama di Kota Yogyakarta 2004-2006), Yogyakarta: Interfidei.
} 
2006 menemukan bahwa: (a) Pada level politik pendidikan yang berfokus pada kebijakankebijakan negara terkait dengan pendidikan agama di sekolah umum ditemui bahwa terdapat dampak yang cukup jelas dari ketegangan politik berkaitan dengan kesepakatan tentang ideologi Negara. Tampak bahwa terdapat kelompok-kelompok Muslim yang masih kesulitan menerima gagasan tentang pemisahan urusan agama dan negara. Bagi kelompokkelompok ini, agama dihayati sebagai pusat tata nilai dan sumber hukum, termasuk dalam kehidupan bernegara dan bermasyarakat. Sementara, kelompok-kelompok Kristiani sudah terbiasa dengan gagasan pemisahan urusan negara dan agama. (b) Pada level sistem pendidikan, semua persoalan yang ada dalam sistem pendidikan di Indonesia ditemukan juga dalam pelaksanaan pendidikan agama di sekolah. (c) Pada level realitas, masyarakat dan siswa sering kali tidak seperti yang dibayangkan oleh para pemegang kebijakan. Banyak kelompok yang mementingkan harmoni dalam hidup dan meletakkan agama sebagai urusan pribadi, bukan urusan yang harus dibawa ke ranah publik.

Di kalangan siswa, sikap santai menghadapi perbedaan agama mudah ditemukan, tetapi oleh pembiasaan yang ditempuh melalui pemisahan siswa pada jam pelajaran agama menanamkan kesadaran dan membentuk cara berpikir mereka bahwa agama sebagai sesuatu yang memisahkan manusia. (d) Pada level institusi pendidikan ditemukan adanya upaya-upaya yang dilakukan oleh kelompok masyarakat melalui lembaga-lembaga pendidikan swasta, mengambil sikap kritis terhadap sistem pendidikan nasional dan khusunya pendidikan agama yang memilih untuk membuat dan mencoba mempraktikkan model pendidikan alternatif.

Kedua penelitian sebagaimana dikemukakan dapat menjelaskan persoalan pendidikan agama di Indonesia saat ini sebagaimana dikemukakan pada bagian pengantar tulisan ini. Penelitian Saerozi telah mengungkapkan realitas politik dan bentuk peleksanaan pendidikan agama di sekolah, sementara Listia, dkk., yang melihat politik dan sistem pendidikan agama juga telah menunjukan kebijakan Negara terhadap pendidikan agama dan sikap kelompok-kelompok masyarakat terhadap kebijakan pendidikan agama tersebut. Tulisan ini secara sadar dibangun untuk memberi pemikiran menanggapi realitas pendidikan agama yang belum banyak membantu literasi agama secara baik di masyarakat untuk membangun sikap beragama yang inklusif di Indonesia. Salah satu konteks yang menghendaki pentingnya pendidikan agama inklusif adalah fenomena konflik dan kekerassan atas nama agama yang marak belakangan ini.

Fenomena konflik dan kekerasan di kalangan kelompok-kelompok pemeluk agama maupun masyarakat secara luas sudah menjadi suguhan yang ramai akhir-akhir ini, baik di Indonesia maupun di belahan bumi lainnya. Fenomena tersebut menurut hemat penulis baiknya mendapat perhatian lembaga-lembaga pendidikan, secara khusus pendidikan keagamaan untuk memosisikan diri sebagai bagian dari solusi terhadap fenomen-fenomena tersebut, diantaranya melalui transformasi substantif pendidikan agama seperti yang sedang dibicarakan ini. Alasan keterlibatan lembaga-lembaga pendidikan sebagai bagian 
dari solusi adalah karena lembaga pendidikan memiliki otoritas membangun kurikulum dan memengaruhi sistem pendidikan, memproduksi pengetahuan dan pengalaman yang membantu proses reflektif maupun aksi setiap naradidik.

Pendidikan agama konfensional disadari atau tidak mengabaikan keberadaan serta hak-hak orang atau kelompok lain, karena fokus pada diri sendiri. Jika terdapat pembelajaran terhadap orang atau kelompok lain di luar dirinya, hal ini tidak signifikan mengubah pandangan yang mendukung klaim kebenaran sendiri. Menurut hemat penulis, pembelajaran agama konfensional yang memberi perhatian pada doktrin atau aqidah eksklusif membentuk panatisme sempit dan memproduksi kelompok-kelompok agama yang memiliki sikap-sikap kebencian (hatred), kemarahan (anger), tidak toleran (intolerance), dan tindakan diskriminatif (discrimination). Sikap-sikap ini berpotensi menimbulkan konflik dan kekerasan di kalangan umat beragama. Bahkan, menjadi lahan subur tumbah dan berkembangnya radikalisme dan ekstrimisme.

\section{Pendidikan Agama Inklusif: jembatan membangun keragaman}

Pendidikan agama inklusif dapat dijadikan alternatif solusi menggantikan pembelajaran agama konfensional yang eksklusif karena (1) pendidikan agama inklusif memiliki tujuan mengubah paradigma pendidikan yang melihat diri sendiri ke melihat diri dalam keberadaannya dengan orang lain. (2) strategi pembelajaran agama inklusif mengutamakan penghargaan dan penggelolaan keragaman. Seiring dengan itu maka, model pendidikan inklusif untuk kepentingan bina damai dapat memengaruhi cara pandang dan sikap terhadap realitas keragaman dan membangun kehidupan bersama yang harmoni dalam perbedaan.

Terkait dengan implementasi Pendidikan Agama Kristen misalnya, Christiani, yang membahas pendidikan perdamaian dengan melihat setting konflik antar agama di Indonesia sebagai konteksnya, menemukan bahwa pendidikan Kristiani yang dilakukan di Indonesia lebih banyak berkisar pada hal-hal kognitif dan dilakukan di kelas dan mengabaikan aspek diakonia. ${ }^{11}$ Pemisahan seperti ini menyebabkan pendidikan Kristiani tidak mengena pada perubahan sosial yang menunjang perdamaian. Oleh karena itu, yang diperlukan adalah suatu model pendidikan Kristiani yang mengintegrasikan diakonia di dalamnya, sehingga terciptalah hubungan dialogis antara pengajaran iman Kristen dan kenyataan konkret dalam masyarakat yang membutuhkan upaya perdamaian. Dengan perkataan lain, terwujudlah praksis dalam pendidikan Kristiani dengan melakukan pendidikan yang berdiakonia sehingga diakonia itu sendiri bersifat reflektif.

Sehubungan dengan proses pendidikan bagi pembentukan aspek kognitif, afektif, dan psikomotor siswa, dalam konteks pengajaran pendidikan agama di Indonesia, apalagi pada wialayah-wilayah yang pernah berkonflik, menarik untuk dilihat pemikiran yang

\footnotetext{
${ }^{11}$ Christiani, "Blessed are The Peacemakers: Christian Religious Education for Peacebuilding in The Pluralistic Indonesian Context"
} 
ditawarkan oleh Jack L. Seymour ${ }^{12}$ dan dikembangkan oleh Cristiani tentang model pendidikan agama sebagaimana dikemukakan berikut ini. Seymour dan Tabita mengemukakan tiga model pendidikan dan pengajaran agama terkait dengan upaya membangun sikap toleran dan saling percaya di kalang siswa beda agama dan etnik dalam rangka membangun kerja sama lintas agama yang harmonis. Ketiga model tersebut adalah (1) in the wall, (2) at the wall, dan (3) beyond the wall.

Pendidikan agama in the wall adalah model pendidikan agama yang hanya mengajarkan agama sesuai dengan agama tersebut, tanpa mendialogkan dengan agama yang lain. Dalam hal ini (1) "Yang lain" terlupakan dalam kurikulum agama. (2) Metode pembelajaran hafalan dan doktriner menyerupai banking education. (3) Membaca "yang lain" dengan tidak bersahabat. Dampaknya adalah sebagai berikut:

1) Kurangnya wawasan peserta didik terhadap "yang lain", apakah mereka yang berbeda keyakinan atau berbeda mazhab/aliran dalam beragama;

2) Mempertegas garis demarkasi antara "aku" dan "kamu", "kita" dan "mereka," seolah-olah polarisasi ini tidak ada titik temunya.

3) Membuka peluang terjadinya kesalahpamahan, karena seringkali kesalahpahaman itu terjadi karena tidak ada informasi dan pengetahuan tentang "yang lain."

4) Kurangnya sikap toleransi, simpati, dan empati kepada mereka yang "berbeda", apakah berbasis pada agama, paham keagamaan, atau lainnya.

5) Menumbuhkan sikap-sikap prejudice (buruk sangka) terhadap mereka yang "berbeda" karena minimnya pengetahuan agama yang mereka miliki.

6) Menumbuh kembangkan sikap superioritas satu agama atas agama yang lain; satu kelompok atas kelompok yang lain.

Pendidikan agama at the wall adalah model pendidikan agama yang tidak hanya mengajarkan agama sendiri saja, tapi juga mendiskusikan relasinya dengan agama yang lain. "Passing over and coming back," mengakui perbedaan dan hak agama lain sekaligus terlibat dalam mencari titik temu.

Strategi pembelajaran agama model ini adalah sebagai berikut:

- Mengajarkan agama dengan mempertimbangkan pluralitas paham keagamaan peserta didik.

- Mengajarkan agama dengan mempertimbangkan pluralitas agama yang ada di Indonesia.

Pendidikan agama beyond the wall adalah model pendidikan agama yang menekankan pada (1) Keberagamaan praksis; (2) mengajak siswa beda agama memerangi

\footnotetext{
${ }^{12}$ Seymour, Jack L., Margaret Ann Crain, and Joseph V. Crockett. 1997, Educating

Christians: The Intersection of Meaning, Learning, and Vocation. Nashville:

Parthenon Press.
} 
musuh utama agama. Dampak dari pendidikan agama beyond the wall adalah sebagai berikut:

- Pertama, membangun solidaritas antar siswa yang berbeda keyakinan; karena berbeda keyakinan tidak boleh menghalangi mereka untuk berinteraksi, berkomunikasi, dan bekerjasama dalam menegakkan nilai-nilai kemanusiaan dan perdamaian.

- Kedua, menghilangkan sikap saling curiga, karena salah satu penyebab kecurigaan adalah minimnya komunikasi dan interaksi antar individu yang berbeda. Seringkali konflik, ketegangan, dan saling curiga karena minimnya pengetahuan dan informasi tentang "yang lain".

- Ketiga, menunjukkan bahwa musuh utama agama itu bukan antar pemeluk agama, tapi adalah korupsi, manipulasi, penindasan, kemiskinan, dan kebodohan. Ini adalah musuh utama (common enemy) agama-agama, dan jika agama diorientasikan untuk memecahkan masalah-masalah seperti ini maka agama akan betul-betul bermakna (meaningful) buat dunia dan manusia.

Dari ketiga model yang dikemukakan, penulis berpendapat bahwa dalam konteks pendidikan agama di Indonesia, model pendidiakan beyond the wall merupakan model ideal yang sudah sepatutnya dikembangkan menjadi pola pengajaran agama yang kontekstual di Indonesia. Model beyond the wall menjadi pilihan yang cocok dengan konteks masyarakat Indonesia yang majemuk, karena model ini tidak hanya memberi ruang bagi hubungan dialogis yang statis, tetapi lebih dari itu adalah mengajak siswa dengan berbagai latarbelakang agama dan etnik untuk bekerja bersama membangun perdamain dan menyuarakan keadilan bagi terciptanya masyarakat yang aman, damai dan harmonis, dengan tetap menghargai keperbedaan masing-masing.

\section{Kesimpulan}

Pemikiran sebagaimana dikemukakan pada bagian-bagian sebelum hendak menegaskan bahwa diperlukan model pendidikan alternatif yang mentransformasi model-model pendidikan agama konfensional yang eksklusif. Dalam kaitan ini penulis menawarkan pendidikan agama inklusif sebagai solusinya. Alasan mengapa pendidikan agama inklusif dapat dijadikan alternatif solusi adalah karena pendidikan agama inklusif mengedepankan nilai-nilai etik dan moral yang dapat diterima kelompok-kelompok masyarakat lebih luas dibanding model-model pendidikan agama konfensional yang lebih memberi perhatian pada doktrin keagamaan sempit. Pengembangan pendidikan agama yang inklusif dalam konteks Indonesia saat ini penting karena masyarakat Indonesia yang plural, termasuk dari dari aspek agama, bahkan, masyarakat Indonesia dikenal sangat religius tetapi penerimaan dan penghargaan satu terhadap lainnya masih menjadi masalah. Dalam konteks demikian, pendidikan agama inklusif yang memberi perhatian pada upaya membangun penyadaran terhadap perbedaan dapat dijadikan model efektif yang mentransformasi pendidikan keagamaan dalam konteks bermasyarakat Indonesia yang majemuk. Pendidikan agama 
inklusif sekaligus dapat dijakan media pembelajaran agama yang dapat membentuk sikap moderat nara didik. Hasil pendidikan agama inklusif dengan sendirinya memberi pembelajaran lierasi agama yang baik kepada masyarakat secara luas untuk membeangun sikap moderasi agama.

\section{Referensi}

Banks, James A., 2001, "Multicultural Education: Characteristics and Goal," dalam Multicultural Education: Issues and Perspectives, ed. James A. Banks and Cherry A. McGee Banks. New York: Jhon Willey \& Sons.Inc.

---------, 2010, “Approaches to Multicultural Curriculum Reform,” dalam Multicultural Education: Issues and Perspectives, ed. James A. Banks and Cherry A. McGee Banks. New York: Jhon Willey \& Sons.Inc.

Christiani, Tabita K., 2005, "Blessed are The Peacemakers: Christian Religious Education for Peacebuilding in The Pluralistic Indonesian Context", Dissertation, The Graduate School of Arts and Sciences Instutute of Religious Education and Pastoral Ministery of Boston College.

---------, Christian Religious Education for Peace, makala The International Conference on Spirituality, Religious Education and Music for Peace Building, Ambon: STAKPN Ambon.

Dewey, John, 1997, Experience and Education, First Collier books ed., The Kappa Delta Pi Lecture Series. New York: Touchstone.

Dupuis, Jacques, S.J., 2001, Toward a Christian Teology of Religion Pluralism, New York: Orbis Books.

Hope S. Antone., 2010, Pendidikan Kristiani Kontekstual: Mempertimbangkan Realitas Kemajemukan dalam Pendidikan Agama. Jakarta: BPK Gunung Mulia.

Kniter, Paul F., 2003, Satu Bumi Banyak Agama, Jakarta : BPK Gunung Mulia.

Listia, dkk., 2007, Probelamtika Pendidikan Agama di Sekolah (Hasil Penelitian Tentang Pendidikan Agama di Kota Yogyakarta 2004-2006), Yogyakarta: Interfidei.

Rumahuru, Y.Z., 2014, Keragaman Sebagai Basis Pembelajaran PAK, Jurnal Mara Christy Vol. V. No. 2, Juli-Desember 2014 Ambon: STAKPN Ambon.

Saerozi, Muh., 2003, Politik Pendidikan Agama dalam Era Pluralisme: Telaah Historis atas Kebijakan Pendidikan Agama Konfensional di Indonesia, Yogyakarta: Program Pascasarjana UIN Sunan Kalijaga.

Seymour, Jack L., Margaret Ann Crain, and Joseph V. Crockett. 1997, Educating Christians: The Intersection of Meaning, Learning, and Vocation. Nashville: Parthenon Press.

Suhadi dkk., 2014, Politik Pendidikan Agama, Kurikulum 2013 di Ruang Publik Sekolah, Yogyakarta: CRCS UGM.

Tilaar, H.A.R. 2000, Pendidikan, Kebudayaan, dan Masyarakat Madani Indonesia:Strategi Reformasi Nasional. Bandung: Penerbit PT Remaja Rosdakarya. ---, 2004, Multikulturalisme: Tantangan-Tantangan Global Masa Depan dalam Transformasi Pendidikan Nasinal. Jakarta: Grasindo. 